\title{
FICTIONAL CHARACTERS AS ALIEN INDIVIDUALS ${ }^{1}$
}

MARTIN VACEK, Institute of Philosophy, Slovak Academy of Science, Bratislava, Slovak Republic

VACEK, M.: Fictional Characters as Alien Individuals

FILOZOFIA, 74, 2019, No 7, pp. $663-668$

The metaphysical nature of fictional characters is a matter of extensive philosophical debate. The related positions come in various flavours and are accompanied by more or less controversial analyses. Possible worlds, or possibilia, are a matter of equally extensive debate, and (controversial) theories about their nature abound. I present an approach to fictional characters which takes advantage of an already-developed approach to so-called alien individuals. I argue that fictional characters and alien individuals instantiate the same properties and they should receive the same analysis. First, I present the theory of linguistic ersatzism. Second, I point out the limitations of the theory. Third, I present the so-called ersatz pluriverse hypothesis, which squares linguistic ersatzism with the possibility of distinct alien individuals. Fourth, I generalise the argument.

Keywords: Modality - Fiction - Fictional Characters - Alien individuals Impossibility

\section{Alien Individuals and Fictional Characters}

Nolan (2002) and Sider (2002) have proposed an economical solution to the problem of alien individuals. Although such individuals are possible, to represent the possibility without committing to non-actual entities turned out to be problematic. One option to avoid the problem is to advocate possible world semantics based on the world-making language: linguistic ersatzism. In this short discussion I will argue that given linguistic ersatzism is a feasible option for alien individuals, it can deal with the problem of fictional characters as well.

According to linguistic ersatzism (henceforth LE), possible worlds are set-theoretical entities that represent modal facts via the expressive tools of our philosophical language. Ideally, in the philosophical language, 'objects and properties can be names for themselves' (Lewis 1986: 145). It has been shown, however, that such a language is not sufficiently rich in certain modal contexts since it either a) fails to name something or b) conflates already-denoted entities. The (possibility of) so-called alien

\footnotetext{
${ }^{1}$ I would like to thank two anonymous reviewers for very helpful comments which substantially improved the final version. My thanks go also members of the Logic, Epistemology and Metaphysics of Fiction band. Namely, thank to Daniela Glavaničová, Miloš Kosterec, Marián Zouhar and Matteo Pascucci.
} 
individuals challenge any theory which rejects mere possibilia and, at the same time, aims at explaining modality by pure actual means. The argument for alien goes as follows: suppose we have a language according to which every actual individual names itself, every actual property names itself and every actual relation names itself. However ideal such language is (it is not vague, it is not ambiguous, it does not suffer from contradictions, etc.), it has its limitations. Namely, the language says that if $\mathrm{x}$ and $\mathrm{y}$ are objects that share the same properties then $\mathrm{x}=\mathrm{y}$. However, it is a strict requirement since representation of distinct, merely possible, individuals collapses into a single one. In brief, LE fails to uniquely represent phenomena that are merely possible and, by definition, have instances without names. I call this the Conflation Problem (henceforth $\mathrm{CP}){ }^{2}$ Moreover, the consequence of $\mathrm{CP}$ is that fictional characters are impossible.

Interestingly, there are several reasons to consider fictional characters impossible. Here is a quick explanation: fictional characters are 'fictional' because they are not actual. Moreover, fictional entities are not even possible; if they were, there would be no way to pick them out, and any way we did settle on would pick out too many of them. In Kripke's famous words:

[g]ranted that there is no Sherlock Holmes, one cannot say of any possible person that he would have been Sherlock Holmes, had he existed. Several distinct possible people, and even actual ones such as Darwin or Jack the Ripper, might have performed the exploits of Holmes, but there is none of whom we can say that he would have been Holmes had he performed these exploits. For if so, which one? (Kripke 1980, 158).

In other words, any account which takes fictional characters as actual individuals faces the worry of their actuality: by definition, they are fictional. On the other hand, an account which takes them to be possible, or possibilia, is gappy in a sense that unless we have a uniqueness conditions, it is rather arbitrary as which individual is which fictional character. Finally, if actuality and possibility exhaust the extent of logical space, fictional individual are impossible ${ }^{3}$.

\footnotetext{
${ }^{2}$ One way to analyse aliens is qualitative in nature. This strategy uses a list of descriptive sentences such as: (i) There is some individual distinct from a, b, c ..., where ' $a$ ', 'b', and 'c' stand for the names of all of the actual individuals. This solution faces a worry, though: the threat of conflating distinct possibilities. First, let us suppose that we apply (i) to account for alien individuals. It is conceivable that two possible worlds differ only with respect to two distinct alien individuals. According to LE, the worlds will be qualitatively indiscernible. However, no two sentences in the world-making language distinguish between these worlds. (i) will therefore identify them with a single set of sentences, contra the initial assumption.

${ }^{3}$ Does such view square with an objection according to which fictional stories are actual and, therefore, fictional individuals must be possible? Yes and no. I agree that if fictional characters correspond to, stand for or represent impossible characters, fictional characters are possible in the same
} 
To analogically paraphrase Kripke's worry:

[g]ranted that there is no alien individual, one cannot say of any possible individual that it would have been that alien individual, had it existed. Several distinct actual individuals might represent alien individuals, but there is none of which we can say that it would uniquely represent an alien. For if so, which one? ${ }^{4}$

The $\mathrm{CP}$ arises once again.

\section{'Impossible' Defined}

'Impossibilising' fictional characters and alien individuals is not novel. Since both kinds of individuals fall outside the sphere of both the actual and the possible, they are impossible. However, impossibility comes in degrees of generality: 'Impossible Ways', 'Logic Violators', 'Classical Logic Violators', 'Contradiction-Realizers', 'Miracle-Bringers', 'Incredulity-Causers', and so on. I agree that fictional characters and alien individuals are not impossible in the above, strictly logical sense - but they are impossible nonetheless. Consider (I):

(I) It is impossible that $\mathrm{P}$ if and only if there is no possible world, $\mathrm{w}$, such that at $\mathrm{w}, \mathrm{P}$.

(I) traditionally represents unrestricted (metaphysical) impossibility along the lines of 'Impossible Ways', 'Logic Violators', 'Classical Logic Violators' and 'Contradiction-Realizers', or what we also call absolute impossibilities. But there is another kind of impossibility. Rather than concerning absolute impossibility, it concerns the expressive limitations of metaphysical theories when it comes to providing for (intuitively) possible scenarios. Put differently, it concerns a theory's theoretical and expressive limits. Consider, for instance, modal realism (henceforth MR) and its metaphysical commitments. MR analyses modal phenomena as truths in possible worlds, defined in the following way:

(W) Possible worlds are maximal mereological sums of spatiotemporally isolated individuals.

way as actual stories can be, and often are, are about inconsistent objects (Cf. Priest 1997). My claim is stronger though: fictional characters are impossible individuals and actual stories are about impossible individuals. Thanks go to an anonymous referee for pointing out this point to me.

${ }^{4}$ Note that (LE) is intended to represent the space of possible worlds and, consequently, does not imply the existence of worlds. 
Given W, there are some intuitive possibilities which, under W-interpretation, turn out to be impossible. Two such impossible scenarios are:

(Nothing) There could be an empty world.

(Islands) There could be spatio-temporarily isolated worlds. ${ }^{5}$

(Nothing) and (Islands) are possible, at least according to (likely controversial) ${ }^{6}$ common-sense intuitions, for if we restrict metaphysical possibility to logical coherence and logical consistency, there is nothing contradictory in supposing (Nothing) and (Islands). Given (W), however, (Nothing) and (Islands) are impossible because MR worlds are non-empty and spatio-temporally isolated individuals. They are MR's theoretical impossibilities as a consequence of particular ontological commitments tied to MR's definitions.

The same diagnosis holds for LE regarding fictional characters and alien individuals. They are not impossible due to their logical inconsistency because they do not figure in non-maximal or non-consistent sets of propositions in the world language. They are theoretically impossible since LE's language is not powerful enough to sufficiently account for their uniqueness - unless LE can be modified.

\section{The Ersatz Pluriverse Approach}

One such modification comes with the so-called Ersatz Pluriverse Approach (henceforth EPA). Nolan (2002) and Sider (2002) have formulated different versions of EPA, both of which share the idea of looking at the (ersatz) modal space as a whole rather than a particular world's point of view. Summing up the Siderian version, the proposal uses a single ersatz pluriverse that represents the totality of possible worlds and individuals all at once (Sider 2002, 287), while Nolan's version provides 'slightly more sophisticated versions of these [ersatzist] theories ... [as] being more holistic in their representations of the possible worlds as a whole than has been traditional' (Nolan 2002, 129).

Importantly, EPA avoids the problem of conflating intuitively distinct possibilities because it avoids quantification over single possible worlds. Rather, the quantification ranges over the plurality of worlds as a whole. The resulting ersatz sentence thus

\footnotetext{
${ }^{5}$ See, for instance, Bricker (2001) and Yagisawa (1988). I agree with an anonymous referee that (Islands) can be seen as a theoretical, rather than common-sense, definition. Lewis (1986, 71 - 72) makes a similar point in stating that completely disconnected spacetimes are not possible but given some passable substitutes, we can provide for them. Since, however, there is no contradiction in the notion, it is still logically possible that there are causally disconnected regions. See also Lewis $(1986, \S 2.8)$ for a more detailed discussion about intuitions within philosophical discourse.

${ }^{6}$ Some people think the opposite, however. For instance, Lewis (1986) does not consider the intuition to be part of our common-sense intuitions.
} 
switches from the world-bound analysis $\exists \mathrm{P} \varphi(\mathrm{P}) \exists \mathrm{Q} \psi(\mathrm{Q})$ to the multiple worlds surrogate $\exists \mathrm{P} \exists \mathrm{Q}[\varphi(\mathrm{P}, \mathrm{Q}) \psi(\mathrm{P}, \mathrm{Q})]$. As a result, alien individuals are to be represented in the following way:

THERE ARE worlds w1, w2, $\ldots$ and THERE ARE properties and relations P1, P2 ... that are distinct from the following actual properties and relations: ..., and THERE ARE possible individuals $x 1, x 2, \ldots$ that are distinct from the following actual individuals: ..., SUCH THAT: ...w1 ... and ... w2 ... and ... (Sider 2002, 287).

According to Sider, the pluriverse sentence ends with open formulas representing each possible world in the form ' $\mathrm{x}_{1}$ in $\mathrm{w}_{1}$ has a property $\mathrm{P}_{1}$ and ...'. According to EPA, modalising does not operate on single possible world surrogates. Rather, the reduction is holistic in the sense that instead of individual worlds, surrogate ersatz pluriverse sentences represent the single pluriverse as a whole ${ }^{7}$. Since the quantifiers occur only in the prefix, we can say that there are distinct non-actual individuals a and $b$, two distinct properties $F$ and $\mathrm{G}$, and two possible worlds such that $\mathrm{a}$ is $\mathrm{F}$ in $\mathrm{w} 1$ and $\mathrm{b}$ is $\mathrm{G}$ in $\mathrm{w} 2$. Since the solution does not conflate two different worlds, the conflation problem does not arise ${ }^{8}$.

EPA addresses Kripke's two worries about fictional characters as well. Recall that the objections get off the ground by supposing that either there is no unique way of denoting ficta or one such way depicts too many of them. Importantly, EPA is a representational approach, meaning that if two phenomena are distinct, the successful analysis can represent them as distinct. As in the case of alien individuals, fictional characters can be picked out uniquely by approaching them holistically.

Interestingly, the above indicates that $\mathrm{CP}$ infects both the representation of fictional characters and the representation of alien individuals because both phenomena present cases of impossibility that differ from the orthodox instances of plain logical inconsistency. This observation brings me to the following argument:

1. Alien individuals are represented holistically via the ersatz pluriverse sentence.

2. Fictional characters are alien individuals ${ }^{9}$.

C. Fictional characters are best represented holistically.

Treating fictional characters as alien individuals is an ontologically and ideologically economical approach. Although such a homogeneous analysis of apparently

\footnotetext{
${ }^{7}$ Cf. Sider $(2002,287-288)$.

${ }^{8}$ Interestingly, Sider (2002) finishes his paper with connecting EPA and the thesis called fictionalism. I understand fictionalism as a different thesis than the thesis I defend in this paper. Thanks an anonymous referee for stressing this point.

${ }^{9}$ An anonymous referee has raised a substantial question: is it relationship between fictional characters analogical, or the matter of identity? In my view, it is the latter.
} 
different phenomena might look suspicious, note that no one has provided good reason to think otherwise. Since the holistic linguistic ersatzist already accepts the ersatz pluriverse sentence, thinking about the phenomena differently is either unjustified or contradicts a widely accepted principle: do not multiply entities beyond necessity.

\section{Bibliography}

BRICKER, P. (2001): Island Universes and the Analysis of Modality. In: Preyer, G. - Siebelt, F. (eds.): Reality and Humean Supervenience: Essays on the Philosophy of David Lewis. Lanham: Rowman and Littlefield.

KRIPKE, S. (1980): Naming and Necessity. Oxford: Blackwell.

LEWIS, D. (1986): On the plurality of worlds. Oxford: Basil Blackwell.

NOLAN, D. (2002): Topics in the Philosophy of Possible Worlds. New York: Routledge Press.

PRIEST, G. (1997): Sylvan's Box: A Short Story and Ten Morals. Notre Dame J. Formal Logic, 38 (4), 573 - 582. [https://doi.org/10.1305/ndjfl/1039540770]

SIDER, T. (2002): The Ersatz Pluriverse. Journal of Philosophy, 99, 279 - 315. [https://doi.org/10.2307/3655585]

SAINSBURY, R. M. (2009): Fiction and Fictionalism. London: Routledge.

YAGISAWA, T. (1988): Beyond Possible Worlds. Philosophical Studies, 53, 175 - 204. [https://doi.org./10.1007/BF00354640]

This paper was supported by grant VEGA No. 2/0117/19: Logic, Epistemology and Metaphysics of Fiction.

Martin Vacek

Institute of Philosophy

Slovak Academy of Science

Klemensova 19

81364 Bratislava 1

Slovak Republic

e-mail: martinvacekphilosophy@gmail.com

ORCID ID: https://orcid.org/0000-0001-9540-4320 